\title{
Os livros
}

\section{Guia dos compostos orgânicos e bio- químicos, Estruturas e nomenclatura, Luís S. Campos, Europress (1987).} (edição cartonada: 3750\$00; edição corrente: 2925\$00)

Pouquíssimo tem sido feito, em Portugal, pela normalização da nomenclatura da Química Orgânica, e menos ainda pela dos compostos bioquímicos. E, no entanto, quanto à Química Orgânica, já há quase um século se acordou, em Genebra, na necessidade premente do estabelecimento de regras internacionais, as quais, no respeitante a hidrocarbonetos e sistemas heterocíclicos, começaram então (em 1892) a ser preparadas, vindo a ser revistas e completadas em Liège (1930) para, após outras revisões e aditamentos, serem finalmente publicadas pela União Internacional de Química Pura e Aplicada (IUPAC).

É certo que o trabalho da própria IUPAC tem sido moroso e não se acha sequer completado; é certo, também, que, no que respeita à Bioquímica, o esforço da IUPAC, primeiro, das comissões conjuntas IUPAC-IUB, mais tarde, e da própria IUB através da sua comissão de nomenclatura $-\mathrm{CBN}$, se tem traduzido mais em "recomendações" do que propriamente em "regras".

Porém, o que ficou establecido desde Genebra (1957) e, depois, em 1969 [Secção C - Grupos característicos que contém os elementos $\mathrm{C}, \mathrm{H}, \mathrm{O}, \mathrm{N}$, Halogénios, $\mathrm{S}$, Se $(\mathrm{Te})]$, viria a constituir só por si as bases sólidas para a nomenclatura de centenas de milhar de outras estruturas, já que a nomenclatura dos hidrocarbonetos e dos sistemas heterocíclicos fundamentais tem aplicação em praticamente todos os grupos de compostos como o comprovam os resultados a que, embora vagarosamente, vêm chegando as comissões de nomencla- tura especializadas, as quais têm esbarrado sobretudo naqueles tipos de estrutura tão diversificados como os lípidos (hidrocarbonetos excluídos), os esteróides e as enzimas. Mas, mesmo aí, existem, quando não "regras", recomendações quanto ao uso de nomes sistemáticos, semi-sistemáticos ou vulgares, Que, por terem saído donde saíram, devem ser cumpridas - seja no Reino Unido como em França ou Portugal - e não ignoradas ou deturpadas, quanto mais não seja porque as recomendações das Comissões de Nomenclatura, tanto da IUPAC como da IUB, ou das comissões conjuntas, vão sempre e insistentemente no sentido de que, em cada país, a nomenclatura seguida o seja em conformidade com a aprovada oficialmente, mesmo quando esta não pareça a mais adequada (sob o ponto de vista linguístico, entenda-se) aos químicos desse país; e de que, em cada país, nas adaptações que sejam indispensáveis, se tente reduzir ao mínimo as alterações que respeitam à construção de nomes, posição de algarismos, abreviaturas, uso de itálico, etc.

O facto é que, entre nós, as próprias regras-base de 1957 são constantemente contrariadas ou confundidas no que se refere a aspectos fundamentais, como sejam a colocação dos algarismos de posição e a ordem dos prefixos respeitantes a substituintes - neste último caso, por geralmente se desconhecer que as próprias regras IUPAC admitem dois critérios.

Acresce, por outro lado, que algumas recomendações das comissões internacionais se confrontam, por vezes, com normas estabelecidas (p. ex., na nomenclatura dos esteróides). Que fazer, nesses casos?

Com a obra que se apresenta pretende-se esclarecer a linguagem da Química Orgânica e da Bioquímica, sem o conhecimento da qual continuará a agravar-se a confusão que afecta e aflige professores, técnicos, investigadores e estudantes.

(do "Prefácio") 


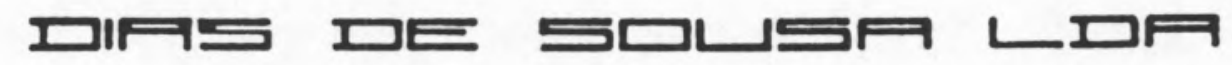

\section{INSTRUMENTAÇ̃̃O ANALITTICA}

Distribuidores exclusivos em Portugal de:

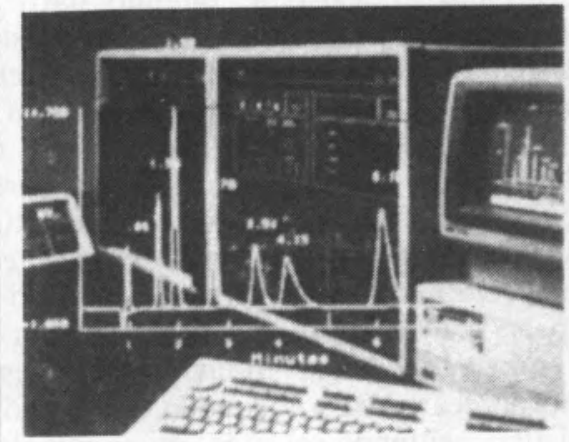

Cromatografia Iónica

DIONEX

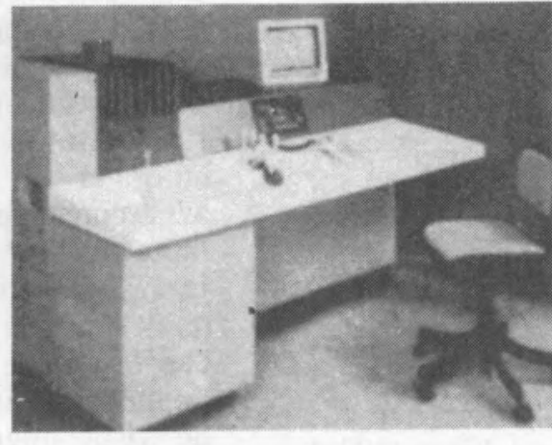

Espectrometria de Emissão

N JOBIn Yvon

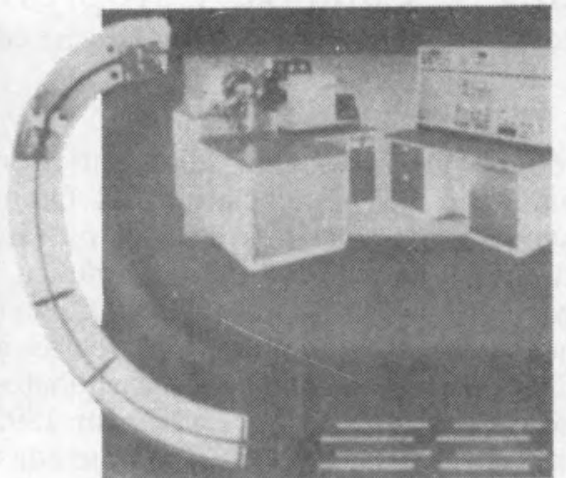

Espectrometria de Massa

KRATTES
ANALYTICAL

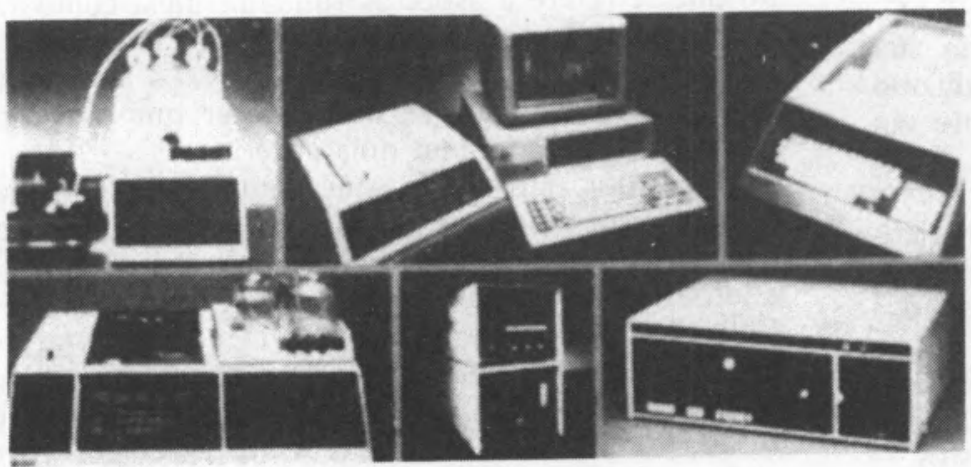

Cromatografia HPLC Integradores-Registadores computarizados

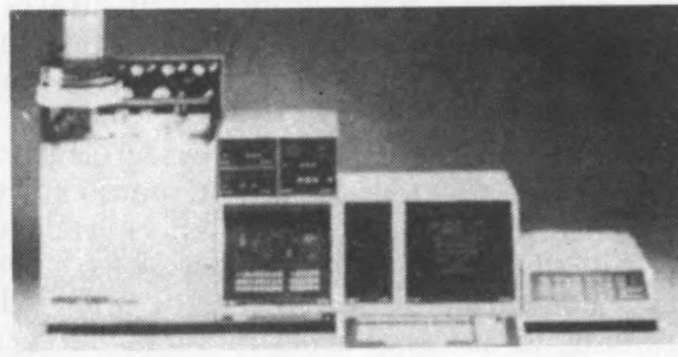

Instrumentação Cientifica

\section{CARLO ERBA}

STRUTERTAZIONE

\section{(S) Spectra-Physics}

Ao vosso serviço com Seriedade, Apoio Técnico e Analítico especializado, Enquadramento laboratorial.

QUINTA DA PIEDADE, LOTE $12 \cdot 10^{\circ} \mathrm{D}$. 2625 PÓVOA DE STA. IRIA

TEL. (01) 2592316 - 2592409

TLX. 43926 DISO P
PRAÇA PEDRO NUNES, 94 4000 PORTO

TEL. (02) 931499 - 933809 TLX. 26250 NSC P 